\title{
Síndrome de lisis tumoral en pediatría
}

\author{
FELIPE CAVAGNARO S. \\ 1. Nefrólogo Pediátrico, Servicio de Pediatría, Clínica Alemana de Santiago. \\ Profesor de Pediatría, Facultad de Medicina CAS-UDD.
}

\begin{abstract}
Tumoral lysis syndrome in pediatrics

Tumor lysis syndrome is a metabolic emergency resulting from the rapid and massive destruction of tumor cells, spontaneously or secondary to cytolytic therapy for cancer. This results in a huge imbalance of internal environment by releasing large amounts of intracellular contents into the interstitial and intravascular space, with serious clinical consequences or even death. The pediatric population is especially at risk of tumor lysis syndrome because it has a high rate of fast-growing tumors, such as those of hematologic origin. Proper recognition of the risk factors that can cause this syndrome, as well as specific prevention and treatment has substantially decreased complications and improved survival in these patients.
\end{abstract}

(Key words: Tumor lysis syndrome, quemotherapy, chronic renal disease, hyperuricemia).

Rev Chil Pediatr 2011; 82 (4): 344-350

\section{RESUMEN}

El síndrome de lisis tumoral es una emergencia metabólica derivada de la rápida y masiva destrucción de células tumorales en forma espontánea o secundaria a terapia citolítica del cáncer. Esta situación produce un enorme desequilibrio del medio interno al liberarse grandes cantidades de contenido intracelular al espacio intersticial e intravascular, con consecuencias clínicas serias e incluso mortales. La población pediátrica está especialmente expuesta a sufrir síndrome de lisis tumoral ya que presenta una tasa elevada de tumores de rápido crecimiento, como son los de origen hematológicos. El adecuado reconocimiento de los factores de riesgo que pueden causar este síndrome, así como su prevención y tratamiento específicos han disminuido sustancialmente las complicaciones y mejorado la sobrevida de estos pacientes.

(Palabras clave: Síndrome de lisis tumoral, quimioterapia, insuficiencia renal, hiperuricemia).

Rev Chil Pediatr 2011; 82 (4): 344-350

Trabajo recibido el 17 de marzo de 2011, devuelto para corregir el 21 de abril de 2011, segunda versión el 21 de abril de 2011, aceptado para publicación el 25 de abril de 2011.

Correspondencia a:

Dr. Felipe Cavagnaro S.

E-mail: fcavagnaro@alemana.cl 


\section{Introducción}

Con el nombre de Síndrome de Lisis Tumoral (SLT) se define a una emergencia metabólica causada por la destrucción masiva y abrupta de células tumorales y la consecuente liberación, hacia el espacio intersticial e intravascular, de una gran cantidad de elementos intracelulares que sobrepasan los mecanismos regulatorios y excretorios normales y, en forma directa o indirecta, pueden condicionar un desequilibrio homeostático con riesgo vital. Aunque esta situación puede ocurrir en forma espontánea, y eventualmente antes de conocerse la existencia de una patología oncológica, es más frecuente que ocurra en el período posterior al inicio de la terapia citotóxica de un cáncer. El desarrollo del SLT en pediatría está fuertemente asociado con, pero no restringido a, cánceres de origen hematológico, como lo son la leucemia linfoblástica aguda y el linfoma de Burkitt, principalmente ${ }^{1-4}$. Los tumores sólidos se asocian infrecuentemente a SLT, en parte porque se hacen sintomáticos más precozmente, la resección quirúrgica de estos disminuye importantemente su masa tumoral, o son menos sensibles a la terapia citotóxica que los tumores hematológicos ${ }^{1,5}$. El SLT usualmente no recurre en un ciclo quimioterápico posterior, presumiblemente porque la mayor tasa de lisis tumoral ocurre en el tratamiento inicial ${ }^{1}$. La incidencia de SLT es muy variable ya que dependerá de variaciones diagnósticas (clínico vs de laboratorio), edades de los pacientes, tipos de cánceres tratados y tratamiento usado, incluyendo medidas preventivas. Se estima que el SLT ocurre en menos del 5\% de los pacientes pediátricos oncológicos tratados con urato oxidasa recombinante ${ }^{2,6}$.

Los factores de riesgo asociados a la presentación de SLT incluyen: tumores de gran tamaño o extensión (tumor $>10 \mathrm{~cm}$ de diámetro o leucocitosis $>50000 \mathrm{x} \mathrm{mm}^{3}$ ), extenso compromiso de la médula ósea, tumores de alta tasa de proliferación celular o aquellos con alta sensibilidad a los agentes quimioterápicos. Entre los factores predisponentes del huésped se encuentran: niveles séricos elevados de deshidrogenasa láctica (mayor al doble del límite superior normal), hiperuricemia o hiperfosfa- temia basal, disfunción renal preexistente, depleción de volumen y oliguria ${ }^{1-6}$. En este sentido, un SLT puede desarrollarse inesperadamente con una baja masa tumoral en presencia de una función renal disminuida ${ }^{1,3,7}$.

\section{Definición}

El desequilibrio metabólico que define al SLT destaca la existencia de hiperuricemia, hiperpotasemia, hiperfosfatemia e hipocalce$\mathrm{mia}^{1-4}$. En 2004, Cairo y Bishop proponen criterios específicos de laboratorio para definir el SLT de laboratorio ${ }^{8}$ (tabla 1). Estos criterios deben estar presentes en el período comprendido entre 3 días antes a 7 días después del inicio de la quimioterapia. El SLT clínico fue definido como la existencia de un SLT de laboratorio más 1 o más de los siguientes criterios clínicos, no atribuibles a los agentes terapéuticos en uso: aumento de la creatininemia $(\geq 1,5$ veces el valor normal alto, ajustado para edad y sexo), arritmias cardíacas/muerte súbita, o convulsiones $^{8}$. La relación entre SLT de laboratorio y SLT clínico es de aproximadamente $3: 1^{3,4}$.

\section{Fisiopatología y cuadro clínico}

Como se observa en la figura 1, la hiperuricemia, la hiperpotasemia y la hiperfosfemia están directamente relacionados a la liberación de elementos intracelulares o al catabolismo de estos, en cambio la hipocalcemia es secundaria al ajuste homeostático necesario para mantener constante el producto calcio-fósforo plasmático $^{1-3,7}$.

Tabla 1. Definición de síndrome de lisis tumoral de laboratorioa

\begin{tabular}{|lcc|}
\hline Elemento & \multicolumn{1}{c}{ Valor } & Cambios desde basal \\
Ácido úrico & $\geq 8,0 \mathrm{mg} / \mathrm{dL}$ & $\uparrow 25 \%$ \\
Potasio & $\geq 6,0 \mathrm{mEq} / \mathrm{L}$ & $\uparrow 25 \%$ \\
Fósforo & $\geq 6,5 \mathrm{mg} / \mathrm{dL}^{\mathrm{b}}$ & $\uparrow 25 \%$ \\
Calcio & $\leq 7,0 \mathrm{mg} / \mathrm{dL}$ & $\downarrow 25 \%$ \\
\hline
\end{tabular}

aRequiere la presencia de 2 o más de las alteraciones enunciadas. bEn adultos considerar fósforo $\geq 4,5 \mathrm{mg} / \mathrm{dL}$. 


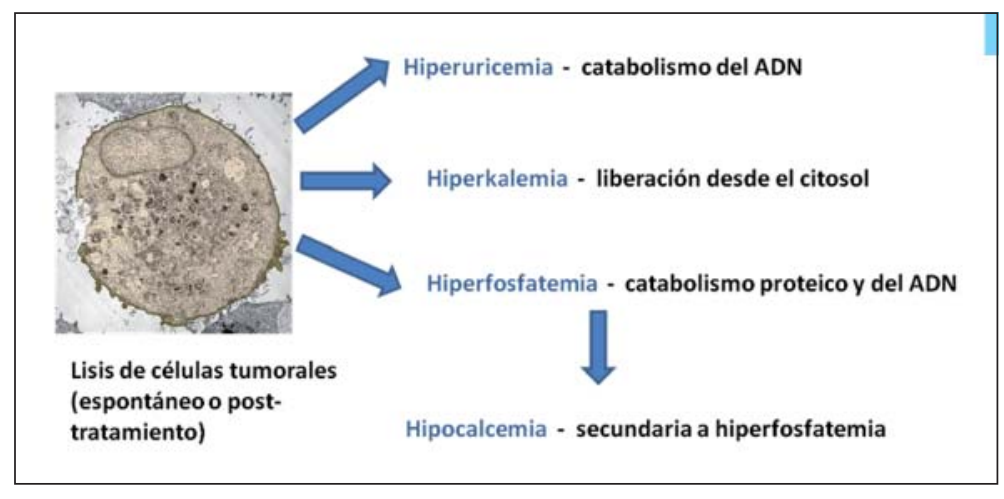

Figura 1. Síndrome de lisis tumoral: las $4 \mathrm{H}$.

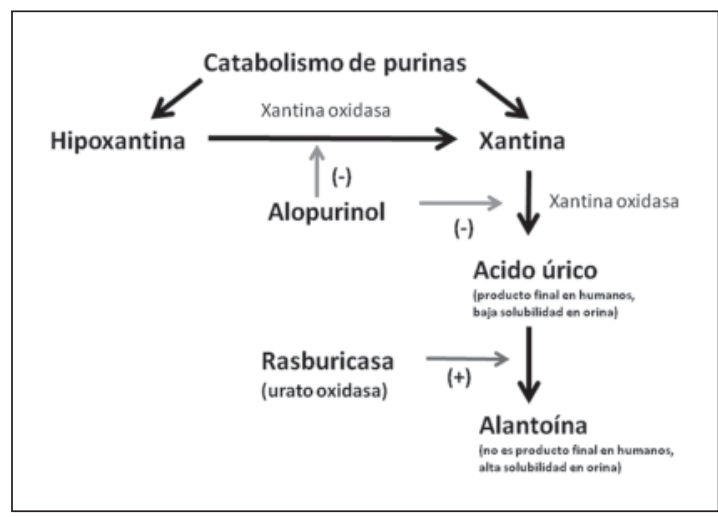

Figura 2. Catabolismo de ácidos nucleicos.

La hiperuricemia se produce por la metabolización de grandes cantidades de purinas provenientes del ADN de las células tumorales hacia ácido úrico (figura 2), y puede desarrollarse dentro de las primeras 48-72 horas post quimioterapia. Esta sobrecarga de ácido úrico sobrepasa la capacidad del túbulo proximal de reabsorberlo, con lo que se cristaliza y precipita en el túbulo distal y colector, apoyado por la secreción de ácido úrico y la acidificación de la orina que ocurre en esa porción tubular. En casos severos también puede haber precipitación de ácido úrico en pequeños vasos intrarrenales. Como es de suponer, esta situación de obstrucción intratubular por cristales empeora más aún en casos de deshidratación y bajo flujo tubular. Sus principales síntomas están muy relacionados con la falla renal que produce (nefropatía por ácido úrico): náuseas, anorexia, vómitos, letargia, oligoanuria y hematuria $^{1,2.7}$.
La hiperpotasemia es la consecuencia esperable de la liberación masiva del principal catión intracelular. El ascenso del potasio sérico ocurre 6 a 72 horas post inicio de la quimioterapia, y sus consecuencias agudas son las más temidas en este síndrome. Puede producirse letargia, debilidad muscular, parestesia o parálisis, y manifestaciones electrocardiográficas que van desde cambios leves en la ondas $\mathrm{T}$ y $\mathrm{P}$, hasta arritmias ventriculares mortales. La hipocalcemia y la acidosis concomitantes pueden agravar esta situación ${ }^{1,3,7}$.

La hiperfosfemia ocurre por liberación de grandes cantidades de fosfatos intracelulares y biomoléculas ricas en fosfatos, como lo son las proteínas y los ácidos nucleicos. Debido a que los linfoblastos pueden contener hasta 4 veces más fosfato intracelular que los linfocitos normales, los tumores linfoides son especialmente propensos a desarrollar esta alteración metabólica. La principal complicación de la hiperfosfemia es la precipitación de fosfato cálcico en los tejidos, incluyendo los túbulos renales colectores. Se ha visto que cuando el producto de solubilidad de ambos (calcio $\mathrm{x}$ fósforo) es $\geq 60$, esta sal comienza a precipitar, con la consecuente hipocalcemia. Sus principales síntomas son náuseas, vómitos, diarrea, letargia, convulsiones y falla renal. También puede causar disrritmias cardíacas incluyendo taquicardia ventricular polimorfa y torsades de pointes al prolongar el intervalo QT. La falla renal por hiperfosfemia parece estar causada por depósitos de fosfato cálcico en los túbulos renales colectores, y eventualmente, en la microvasculatura intrarrenal. La hipocalcemia, 
aunque generalmente asintomática, puede producir irritabilidad neuromuscular con calambres, tetania y convulsiones, anorexia y vómitos, arritmias cardíacas y prolongación del tiempo de coagulación ${ }^{1,2,3,7}$.

Cómo ya ha sido mencionado antes, el daño renal agudo en SLT se produce principalmente por precipitación de ácido úrico y fosfato cálcico a nivel de los túbulos renales, y puede evolucionar hacia la falla renal, usualmente oligúrica, lo que empeora el manejo de la patología tumoral y, en especial, su pronóstico vital $^{1,4,7}$. Dado que en casos de SLT espontáneo continúa habiendo captación de fosfatos por las células malignas en duplicación, es más probable que la causa de falla renal en este tipo de SLT sea la nefropatía por ácido úrico, en comparación con el SLT post quimioterapia, en el que los depósitos de fosfato cálcico parecen tener mayor importancia ${ }^{4}$. Otras causas de daño renal agudo también deben ser investigadas, como nefrotoxicidad por drogas, obstrucción urinaria extrínseca, infiltración renal tumoral y disminución de la volemia efectiva (prerrenal) $^{9-11}$.

\section{Prevención y tratamiento}

La sospecha de SLT debiera siempre existir en pacientes oncológicos con factores de riesgo presentes (tabla 2), ya que la principal arma terapéutica es la prevención (tabla 3).

Tabla 2. Estratificación de factores de riesgo de síndrome de lisis tumoral según tipo de tumor y recuento de leucocitos

\begin{tabular}{|c|c|c|c|c|c|}
\hline Riesgo & $\begin{array}{c}\text { LLA } \\
\text { (leucocitos/uL) }\end{array}$ & $\begin{array}{c}\text { LMA } \\
\text { (leucocitos/uL) }\end{array}$ & $\begin{array}{c}\text { LLC } \\
\text { (leucocitos/uL) }\end{array}$ & Otros* & LNH \\
\hline Riesgo alto & $\geq 100000$ & $\geq 50000$ & & & $\begin{array}{l}\text { Linfoma de } \\
\text { Burkitt,linfoma } \\
\text { linfoblástico, LLA-B }\end{array}$ \\
\hline Riesgo intermedio & $50000-100000$ & $10000-50000$ & $\begin{array}{l}10000-100000 \\
\text { tratados con fluda- } \\
\text { rabina }\end{array}$ & $\begin{array}{l}\text { Proliferación } \\
\text { rápida y respuesta } \\
\text { terapéutica rápida } \\
\text { esperable }\end{array}$ & LCBGD \\
\hline Riesgo bajo & $\leq 50000$ & $\leq 10000$ & $\leq 10000$ & Resto de pacientes & LNH indolente \\
\hline
\end{tabular}

LNH: linfoma no Hosgkin; LLA: leucemia linfoblástica aguda; LMA: leucemia mieloide aguda; LLC: leucemia linfocitaria crónica; LLA-B: LLA de células B; LCGBD: linfoma de células B grande y difuso. *Otros tumores hematológicos y los tumores sólidos.

Tabla 3. Algoritmo de prevención y manejo de la hiperuricemia en SLT

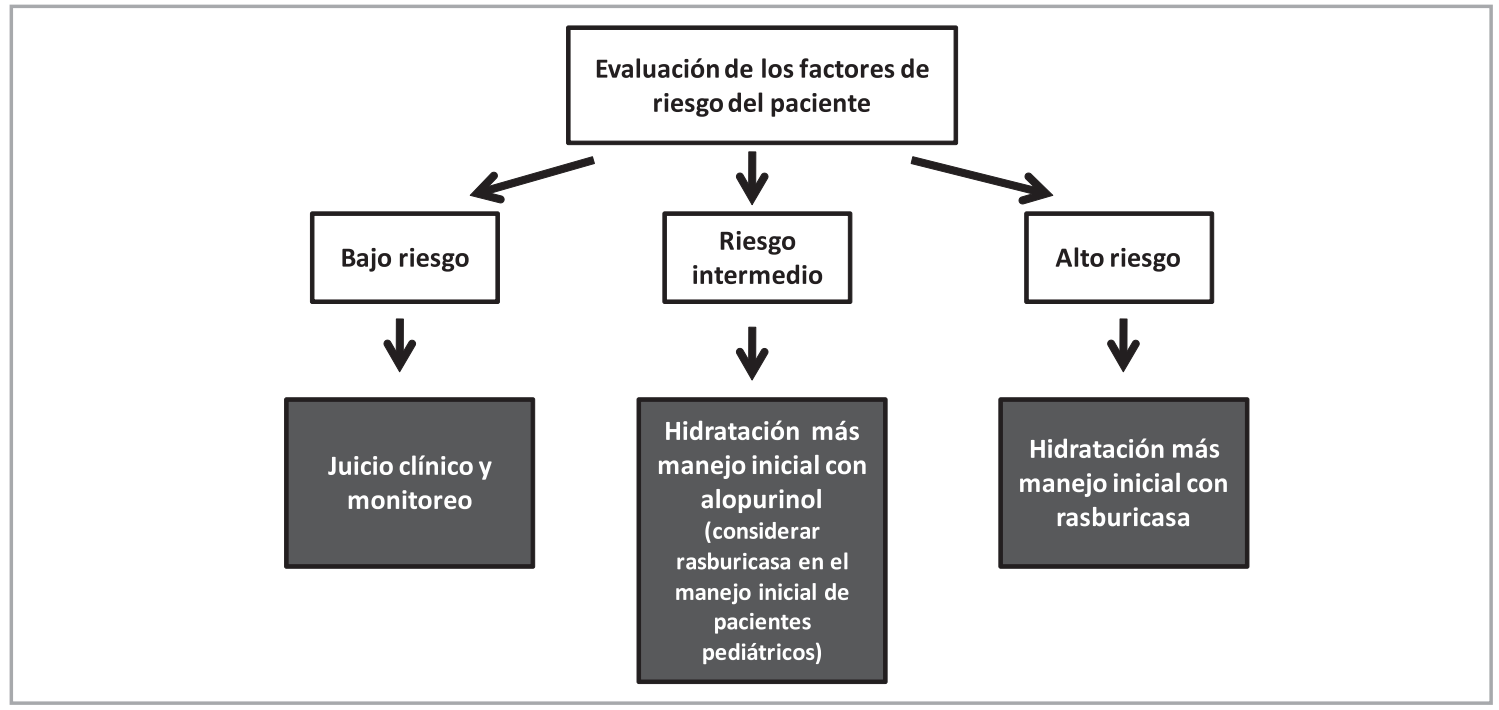


Entre los exámenes iniciales de laboratorio del SLT se debe incluir un hemograma completo con recuento reticulocitario, electrolitos plasmáticos, gases venosos, calcio, fósforo, magnesio, ácido úrico, nitrógeno ureico en sangre, creatinina, deshidrogenasa láctica y pruebas hepáticas. Un análisis de orina nos permitirá conocer la gravedad específica, el tipo de cristales y cilindros, y/o hematuria. $\mathrm{Si}$ hay hipocalcemia, chequear calcio iónico y albuminemia. En caso de hiperpotasemia confiable, complementar en forma inmediata con un ECG.

En casos de masas abdominales y pélvicas, o en tumores diseminados, es conveniente realizar un estudio de imágenes (ecografía o tomografía axial computarizada) para evaluar posible compresión o infiltración renal y uropatía obstructiva.

Una vez detectado el SLT es importante iniciar un monitoreo cercano y frecuente de los parámetros clínicos, incluyendo diuresis, y de los marcadores séricos relevantes de este síndrome (cada 4-6 horas al comienzo), especialmente en los primeros 3 días, en que se produce la mayor cantidad de lisis celular ${ }^{1,5,6}$. En este contexto, parece razonable ubicar al paciente en una unidad de mayor complejidad. Como es de suponerse, el SLT espontáneo suele tener mayor gravedad clínica ya que no ha habido oportunidad de iniciar un tratamiento profiláctico 5 .

Cómo profilaxis y manejo inicial, el elemento terapéutico más importante es la hidratación intravenosa agresiva, lo que mediante un incremento en la velocidad de filtración glomerular, promueve la excreción de ácido úrico y fosfatos ${ }^{1-7}$. Esta medida debiera comenzarse al menos 24 horas previo al inicio de la quimioterapia y mantenerla por 48 horas luego de finalizada. Se debe evaluar previamente el riesgo de sobrecarga de volumen e insuficiencia cardíaca congestiva en pacientes cardiópatas o con enfermedad renal avanzada. La cantidad de líquido a aportar debe, al menos, doblar los requerimientos de mantención diarios, esto es, $2-3 \mathrm{~L} / \mathrm{m}^{2} /$ día o $200 \mathrm{ml} / \mathrm{kg} /$ día en menores de 10 kilos de peso. El débito urinario debe lograr un flujo $\geq$ a $100 \mathrm{ml} / \mathrm{m}^{2} /$ hora o $4-6 \mathrm{ml} / \mathrm{kg} /$ hora si pesa menos de $10 \mathrm{~kg}$, con una gravedad específica urinaria $\leq 1010$; ocasionalmente se debe agregar diuréticos (manitol y/o furosemida) para lograr esta diuresis. La solución a infundir es $3 / 4$ partes de suero glucosado $5 \%$ y $1 / 4$ como solución salina fisiológica, sin adicionar potasio o fosfatos en esta solución.

La alcalinización del paciente persigue la idea de aumentar sustancialmente la solubilidad del ácido úrico en la orina, lo que se consigue adecuadamente con un $\mathrm{pH}$ urinario entre 7 y 8 . Esta misma conducta modifica mínimamente la solubilidad de la xantina e hipoxantina. La alcalinización urinaria puede lograrse adicionando 40 a $60 \mathrm{mEq} / \mathrm{L}$ de $\mathrm{NaHCO}_{3}$ al suero de hidratación. Debe tenerse en cuenta que esta misma terapia puede producir alcalosis metabólica y estimula a precipitar cristales de fosfato cálcico en los túbulos colectores, por lo que su uso en la actualidad es controversial, especialmente con el uso de urato oxidasa recombinante, en que el control de la hiperuricemia es excelente ${ }^{2,3,5}$.

Con respecto al manejo de la hiperuricemia en forma específica, por décadas ha sido usado el Alopurinol, un inhibidor competitivo de la xantina oxidasa, enzima que metaboliza las purinas hacia ácido úrico (figura 2). $\mathrm{Su}$ uso debe ser iniciado no más tarde que 12-24 $\mathrm{h}$ antes de iniciar quimioterapia de inducción, y mantenido hasta que los niveles de ácido úrico se han normalizado, el tamaño tumoral ha disminuido y los parámetros de laboratorio han regresado a niveles de bajo riesgo de SLT. Si bien ha demostrado reducir la incidencia de nefropatía por ácido úrico en SLT, el Alopurinol tiene algunos bemoles: a) sólo actúa sobre la formación de nuevo ácido úrico, no sobre la hiperuricemia ya existente; b) su uso puede gatillar excesivos niveles de xantina a nivel de orina, la cual también pude causar obstrucción intratubular; c) al ser un inhibidor de la xantina oxidasa, el Alopurinol disminuye la depuración de otras drogas que usan esta vía metabólica (ej.: 6-mercaptopurina) requiriendo reducción en su dosificación; d) puede gatillar reacciones alérgicas $^{1-7}$. Por ser de excreción renal, se recomienda disminuir la dosis de Alopurinol en caso de insuficiencia renal. Su dosificación se nuestra en tabla 4.

La incorporación terapéutica de la urato 
Tabla 4. Administración de agentes hipouricemiantes

\begin{tabular}{|ll|}
\hline Alopurinol & $\begin{array}{l}\text { Oral: } 100 \mathrm{mg} / \mathrm{m}^{2} / \mathrm{dosis}, \mathrm{c} / 8 \mathrm{~h} \text { ó } 10 \mathrm{mg} / \mathrm{kg} / \mathrm{día} \\
\text { dividido } \mathrm{c} / 8 \mathrm{~h} \text { (máx } 800 \mathrm{mg} / \mathrm{día}) \\
\text { iv: } 200-400 \mathrm{mg} / \mathrm{m}^{2} / \text { día dividido en } 1 \text { a } 3 \\
\text { dosis (máx } 600 \mathrm{mg} / \mathrm{día})\end{array}$ \\
Rasburicasa* & $\begin{array}{l}\text { Riesgo alto: } 0,2 \mathrm{mg} / \mathrm{kg} \\
\text { Riesgo intermedio: } 0,15 \mathrm{mg} / \mathrm{kg} \\
\text { Riesgo bajo: } 0,1 \mathrm{mg} / \mathrm{kg}\end{array}$
\end{tabular}

*Terapia puede durar de 1 a 7 días, dependiendo de control de ácido úrico.

oxidasa recombinante (rasburicasa) revolucionó el tratamiento de la hiperuricemia en el SLT e hizo innecesaria la alcalinización de la orina por esta razón (figura 2). Esta enzima, que no poseen los primates superiores, permite la degradación del ácido úrico hacia alantoína, un metabolito 5 a 10 veces más soluble en orina que el ácido úrico. $\mathrm{Su}$ acción es rápida (dentro de 4 horas) y no induce acumulación de xantina. Se ha visto conjuntamente una normalización de la función renal con el uso de esta droga en estos pacientes. Entre las desventajas de su uso están: a) su alto costo, por lo que debe ser reservado para pacientes con muy altos niveles de ácido úrico o con evidencias de nefropatía por ácido úrico; b) el riesgo de desencadenar una hemólisis masiva en pacientes con déficit de G6PD por la generación de peróxido de hidrógeno en el metabolismo de ácido úrico hacia alantoína; c) el riesgo potencial de una reacción alérgica severa por ser un producto biológico. No debe usarse en adolescentes embarazadas o lactando. Es importante destacar que, a temperatura ambiente, la rasburicasa continúa degradando ácido úrico en la sangre extraída, por lo que estas muestras deben ser puestas rápidamente en hielo y procesadas, idealmente, dentro de las siguientes 4 horas $^{1-7}$. Su dosificación se muestra en la tabla 4. No requiere ajustes en insuficiencia renal.

El manejo de la hiperpotasemia en el SLT es lo que requiere mayor celeridad, ya que conlleva un significativo riesgo vital. Junto con su detección $(\mathrm{K}+\geq 6 \mathrm{mEq} / \mathrm{L})$ debe iniciarse un monitoreo electrocardiográfico cercano, al tiempo que se implementan las medida para contrarrestarla. Se debe optimizar la diuresis y la función renal, y suspender los aportes de po- tasio en los aportes intravenosos. En pacientes asintomáticos y con discreta elevación del $\mathrm{K}+$, puede iniciarse aportes de resinas de intercambio iónico. Cuando el paciente está sintomático, se deben implementar medidas de acción más inmediata como infusión de insulina + glucosa, gluconato de calcio, bicarbonato de sodio, nebulizaciones de salbutamol o, incluso, diálisis. Una hipocalcemia concomitante debe ser investigada y corregida precozmente para evitar un mayor riesgo de arritmias cardíacas ${ }^{1,5,7}$.

La hiperfosfemia debe manejarse suspendiendo todos los aportes parenterales de fosfatos, optimizando la hidratación y diuresis, $\mathrm{y}$ usando quelantes intestinales de fosfatos, como lo son el hidróxido de aluminio (50 a $150 \mathrm{mg} / \mathrm{kg} /$ día, dividido c/6 h. Limitar su uso a 48 horas para evitar toxicidad por aluminio) o el sevelamer (20 a $40 \mathrm{mk} / \mathrm{kg} /$ dosis, máx 800 $\mathrm{mg}$, c/8 horas). El uso de carbonato de calcio tiene el riesgo de aportar calcio, el que puede elevar el producto calcio $\mathrm{x}$ fósforo y precipitar cristales de fosfato cálcico, por lo que no debe usarse en pacientes con calcemia normal a alta. Al igual que con otros desbalances electrolíticos, la hiperfosfemia refractaria puede requerir diálisis. La hipocalcemia asociada a hiperfosfemia no debe ser corregida agresivamente si es asintomática, ya que aumenta el riesgo de precipitación de fosfato cálcico en orina (y otros lugares), empeorando la uropatía obstructiva. Aunque usualmente se resuelve junto con el SLT, algunos casos de hipocalcemia sintomática pueden requerir aportes de gluconato de calcio intravenosos $50-100 \mathrm{mg} / \mathrm{kg}$ i.v. administrado lentamente y con monitoreo ECG. Esta situación también puede requerir diálisis ${ }^{1-7}$.

\section{Reemplazo renal}

Pese a un adecuado y precoz manejo farmacológico de un SLT, algunos pacientes con cuadros refractarios al manejo médico pueden requerir de diálisis aguda. La necesidad de esta técnica tuvo un marcado descenso luego de la incorporación terapéutica de la rasburicasa. Entre las causas más frecuentes de reque- 
rir reemplazo renal está la insuficiencia renal aguda, pero también puede requerirse en casos de hiperpotasemia severa, hiperfosfemia e hipocalcemias refractarias y acidosis metabólica severa. La decisión de qué tipo de terapia de reemplazo renal aguda usar en SLT dependerá de la edad del paciente, su condición clínica, los recursos de que se disponga y de la experiencia del equipo tratante. En pacientes escolares mayores y hemodinámicamente estables, la hemodiálisis es la terapia de elección por la rapidez en controlar los desequilibrios metabólicos. La diálisis peritoneal, más frecuentemente usada en pediatría, tiene peor depuración de fosfatos y ácido úrico que las técnicas vasculares. Las terapias continuas, como la hemofiltración veno-venosa continua, son alternativas promisorias en pacientes pequeños con compromiso hemodinámico o con mala tolerancia a las otras técnicas ${ }^{1-7}$.

\section{Conclusión}

El SLT constituye una emergencia médica provocado por un grave disturbio metabólico secundario a la destrucción masiva de células tumorales, con la consiguiente liberación de elementos intracelulares que supera la capacidad depurativa del organismo. Sus consecuencias pueden ser letales en corto plazo para quien lo padece. Si bien fuertemente asociado a tumores hematológicos, el desarrollo futuro de agentes quimioterápicos más efectivos pueden ocasionar que el SLT sea más frecuente de observar en otros tumores. Dado su importancia clínica, el precoz reconocimiento de este síndrome o de los factores de riesgo que estimulan su desarrollo es de enorme importancia clínica, ya que su prevención sigue siendo la piedra angular en su manejo. En aquellos casos en que las alteraciones metabólicas igual se desarrollan, el tratamiento actual, enfocado fisiopatológicamente, ha mejorado sustancialmente la morbimortalidad de este cuadro clínico.

\section{Referencias}

1.- D'Orazio J: The tumor lysis syndrome: an oncological and metabolic emergency. En: Kiessling S. Goebel J y Somers M, ed. Pediatric Nephrology in the ICU, BerlinHeidelberg, Editorial Springer-Verlag 2009; 201-18.

2.- Coiffer B, Altman A, Pui CH, Younes A, Cairo M: Guidelines for the management of pediatric and adult tumor lysis syndrome: an evidence-based review. J Clin Oncol 2008; 26: 2767-78.

3.- Abu-Alfa A, Younes A: Tumor lysis syndrome and acute kidney injury: evaluation, preservation, and management. Am J Kidney Dis 2010; 55 (S3): S1-S13.

4.- Larson $\mathrm{R}$, Pui $\mathrm{CH}$ : Tumor lysis syndrome. En: Up to date On line $2010 \mathrm{http}: / / \mathrm{www} . u p t o d a t e . c o m /$ contents/tumor-lysis-syndrome?source=search_result \&selectedTitle=1\%7E94

5.- Rampello E, Fricia T, Malaguarnera M: The management of tumor lysis syndrome. Nat Clin Pract Oncol 206; 3:438-47.

6.- Zonfrillo M: Management of pediatric tumor lysis syndrome in the emergency department. Emerg Med Clin N Am 2009; 27: 497-504.

7.- Davidson M, Thakkar S, Hix J, Bhandarkar N, Wong A, Schreiber M: Pathophysiology, clinical consequences, and treatment of tumor lysis syndrome. Am J Med 2004; 116: 546-54.

8.- Cairo M, Bishop M: Tumor lysis syndrome: new therapeutic strategies and classification. Br J Haematol 204; 127: 3-11.

9.- Darmon M, Ciroldi M, Thiery G, Schlemmer B, Azoilay $E$ : Clinical review: specific aspects of acute renal failure in cancer patients. Critical Care 2006; 10: 1-7.

10.- Givens $M$, Crandall J: Renal complications in oncological patients. Hematol Oncol Clin 2010; 24: 567-75.

11.- Benoit D, Hoste E: Acute kidney injury in critically ill patients with cancer. Crit Care Clin 2009; 26: 151-79. 